\title{
The influence of distant coal seam edges on seismic hazard during longwall mining
}

\author{
Lukasz Wojtecki $[$ · Iwona Gołda $(\mathbb{D} \cdot$ Maciej J. Mendecki $(\mathbb{C}$
}

Received: 14 April 2020 / Accepted: 5 October 2020 / Published online: 14 October 2020

(C) The Author(s) 2020

\begin{abstract}
Underground coal seam mining has been carried out in the Upper Silesian Coal Basin, Poland, for many years and with a simultaneous increase in exploitation depth. Frequently, coal seams are not fully extracted due to numerous reasons which lead to their edges and remnants remaining in the rock mass. Even in the case of the full extraction of a coal seam, mining usually ends at the border of a protecting pillar to protect underground or surface objects, sometimes at the border of the mining area, or some distance from the old goaf or high throw fault. Extraction of subsequent coal seams in
\end{abstract}

\begin{abstract}
Highlights
We reviewed a catalogue of mining tremors that occurred during longwall mining of coal seam no. 408 in one of the hard coal mines in the Upper Silesian Coal Basin, Poland. The seismological parameters and distributions have been applied to determine the correlation between edges of distant coal seams, located over the longwall panel, and occurrence of strong tremors. The performed analysis indicates influence of current mine workings on stressstrain equilibrium, established in the rock mass.
\end{abstract}

\section{Ł. Wojtecki $(\bowtie)$}

Central Mining Institute, 1 Gwarków Square, 40-166 Katowice,

Poland

e-mail: lwojtecki@gig.eu

I. Gołda

Faculty of Mining, Safety Engineering and Industrial Automation, Silesian University of Technology, 2 Akademicka Str, 44-100 Gliwice, Poland

\section{J. Mendecki}

Faculty of Environmental Sciences, University of Silesia in

Katowic, 60 Będzińska Str, 41-200 Sosnowiec, Poland an analogous range results in a cluster of coal seam edges remaining. In the vicinity of the mentioned remainders, the disrupted stress distribution is expected. The infraction of the aforementioned equilibrium repeatedly results in the occurrence of strong mining tremors. The observations from the studied coal seam no. 408's longwall panel indicated that mining works are able to disturb the present stress-strain equilibrium in the area of the edges of other coal seams, even if they are located at a greater vertical distance away. The seismological parameters and distributions have been applied for this purpose.

Keywords Seismic hazard · High-energy tremors · Coal seams edges

\section{Introduction}

Longwall mining is the most popular method of underground hard coal mining in Poland and in the world. It is due to the opportunity for the mechanization of mining system, which increases the concentration of extraction, the efficiency and the cost reduction. In longwall mining, the long wall of hard coal is mined by a shearer. It moves along the coalface, between two headings, called main gate and tail gate. The block of mined hard coal is called the longwall panel. In Polish conditions, longwall panels usually are approximately 150-300 m wide (longwall length) and approximately from hundreds of metres to $2000 \mathrm{~m}$ long. The shearer cuts a slice of coal on each pass, usually $0.6-1 \mathrm{~m}$ thick. The working area is 
protected by the movable hydraulically operated roof supports. As the longwall mining progresses, the roof above the mined coal seam is allowed to collapse behind the longwall face and form a goaf. Main gate and tail gate can be kept behind the passing longwall face or not. Hard coal loosened by a shearer falls down on face scraper conveyor and is carried out mostly to the main gate, where another chain scraper conveyor, crushing plant and conveyor belt are installed.

Seismic events in mines are provoked partially (triggered/mining-tectonics seismicity) or completely (induced/mining seismicity) by mining operations. These types of seismicity occurs in rock mass which is impacted by underground mining due to different processes, e.g. cavity collapse, pillar burst, tensional fault in roof rocks, a slip of a normal fault, a slip of a thrust fault in the condition of maximal horizontal stress or shallow (near horizontal) thrust faulting (Hasegawa et al. 1989). Seismic events in mines are often called mining tremors.

Seismic activity is a factor which accompanies the underground extraction of coal seams in the Upper Silesian Coal Basin (USCB), Poland, and in general, it can be divided into two groups: "mining-tectonics" and "mining" seismicity (Stec 2007). "Mining-tectonic" seismicity results from the interaction between mining and tectonic factors (Stec 2007). Mine works, especially longwall mining, can trigger a slip of the pre-existing fault plane (Stec 2007; Wojtecki et al. 2016). Hypocentres of these types of mining tremors are located in the vicinity of naturally occurring faults. The energy of these tremors is usually higher than the energy of tremors caused directly by mining. "Mining" seismicity is associated directly with the processes resulted from hard coal extraction. In this case, the hypocentres of tremors "move" correspondingly with the mine works advance (Kusznir et al. 1980; Drzęźla et al. 1991). Hypocentres of these tremors are located in the mined coal seam or directly in roof rocks and/or in floor rocks. The processes responsible mainly for the occurrence of this type of tremors are explosions, if the hypocentre is ahead of longwall face (Stec 2007; Stec and Wojtecki 2011), and implosion, if the hypocentre is behind the longwall face and the caving of roof rocks is forced (Wojtecki et al. 2016). Sometimes these mechanisms are combined with the slip of rock blocks. A larger share of slip mechanism is present in the hypocentres of mining tremors, located in the layers of competent roof rocks, e.g. sandstones (Stec 2007; Stec and Wojtecki 2011; Stec 2012; Stec 2017). The energy of mining tremors caused by the fracturing of competent rocks is usually high.

Because of the long-term extraction of many coal seams, their edges and remnants are present in the rock mass, causing uneven stress distribution in their vicinity (Dubiński and Konopko 2000). The rock mass is destressed in the surroundings of goaf, and the stress level increases close to coal seam edges. The maximum stress level in the rock mass is found on the side of an unmined coal body. The stress decreases as the distance from the coal seam edge increases and reaches the normal level for the depth. The presence of a coal seam edge affects the stress level in the rock mass, which is higher than would be expected at the particular depth of deposition. In the selected hard coal mine, the horizontal impact range of a coal seam edge on the stress level in the rock mass is assumed to be up to $20 \mathrm{~m}$ in the direction of the mined coal seam and a maximum of $40 \mathrm{~m}$ in the direction of the unmined coal body.

Stress accumulation near the coal seams edges may be observed for a long time, even up to 20 to 30 years after the end of underground workings (Dubiński and Konopko 2000). Mining tremors correlated with the stress release in the vicinity of the coal seams edges are usually strong. If many coal seams edges are located in a narrow area, e.g. at the border of the protecting pillar, high stress level in the rock mass should be expected. The seismic energy released because of pillar burst is high, and it reaches a comparable level with the energy released by "mining-tectonic" tremors. The strain energy accumulated in the protecting pillar is more likely to be released when mine works are conducted within the pillar or in its vicinity, even if the scope of those works is small.

In Polish hard coal mines, during the planning of underground works and in accordance with Polish law, only the edges and remnants of coal seams deposited $160 \mathrm{~m}$ above and $60 \mathrm{~m}$ below the selected coal seam are taken into consideration for rockburst hazard evaluation. It is assumed that these edges may affect the stress level in the mined coal seam. Other edges are not considered, although they may be responsible for stress increasing in some parts of the rock mass and occurrence of strong mining tremors.

In this article, the results of a study on the longwall mining of coal seam no. 408, which was performed in one of the underground hard coal mines in the Upper Silesian Coal Basin, Poland, are presented. It was shown that far-distant and old coal seams edges are also a 
source of seismic threat. These hazardous coal seams edges were $325 \mathrm{~m}$ above coal seam no. 408, and they were formed at least 13 years before extraction of coal seam no. 408 began. The tremors which were observed during mining operations were strong. Their energies mainly ranged between $10^{5}$ and $10^{6} \mathrm{~J}$, but at the border of the pillar for drifts located $840 \mathrm{~m}$ below the surface, the strongest tremor with the energy of $1 \cdot 10^{8} \mathrm{~J}$ occurred.

The correlation between high-energy tremor occurrence and the edges of far-distant coal seams was carried out. An attempt to investigate how the current mine works can influence the stress release through seismicity in the area of remnants in shallower coal seams was made. For this purpose, the distributions of energy and frequency of mining tremors and the Benioff plot were applied. With the use of 1D or 2D distributions, it is possible to correlate the occurrence of mining tremors with the geological or mining factors, influencing the stress regime in the rock mass. On the Benioff plot, it is possible to determine the deflation periods, when an accumulation of strain energy in rocks takes place, and the acceleration periods, when accumulated strain energy is easily released. Distinguished periods on the Benioff plot were correlated with the edges of fardistant coal seams. Moreover, the GR $b$ parameter was calculated, as well as probability of the occurrence of strong tremors. Some relationships between these quantities and edges of far-distant coal seams were observed.

\section{Geological and mining conditions}

The thickness of coal seam no. 408, where the studied longwall panel with caving was designed, ranged from approximately 1.6 to $2.6 \mathrm{~m}$. The lowest level of thickness was present near the longwall cross-cut, and it increased to the east (the direction of the longwall face advance). The coal body was locally interbedded with a thin layer of shale $(0.05-0.15 \mathrm{~m})$. The seam dip was small and ranged from $6^{\circ}-16^{\circ}$, and the dip direction was generally from NE to SW. According to Polish law, this coal seam was classified as having the highest (2nd) degree of rockburst hazard.

The longwall panel was 197.5-202.4 m wide and approximately $1340 \mathrm{~m}$ long (approximately $1348 \mathrm{~m}$ along the tail gate and $1332 \mathrm{~m}$ along the main gate). The longitudinal dip of the longwall ranged from $5^{\circ}$ to $16^{\circ}$, while the traverse dip was between $0^{\circ}$ and $7^{\circ}$. The longwall panel was at a depth of between approximately
1010 and $1050 \mathrm{~m}$ below the surface, resulting in high levels of stress. The theoretical values of the vertical principal stress equalled approximately 25-26 MPa.

The longwall face height ranged from 1.91 to $2.48 \mathrm{~m}$. The start of the longwall mining began at the longwall cross-cut, located to the west, near the upthrow side of a fault with a throw of $50 \mathrm{~m}$. The longwall mining ended near the border of the protecting pillar for drifts at the level of $840 \mathrm{~m}$, located to the east. The longwall panel was located to the south from the goaf which was also excavated in coal seam no. 408 but around 5 to 6 years earlier. The tail gate was separated from the old goaf by a rib of coal, approximately $5 \mathrm{~m}$ wide.

The floor rocks of coal seam no. 408 were composed of shales, sandy shales and sandstones. To the east and south-east side of the longwall panel, the floor rocks were interbedded with the layer of hard coal. According to the profile captured from the borehole, drilled within the longwall panel (Fig. 1a) in the floor rocks, the thickness of the shales reached $4.47 \mathrm{~m}$, the off-balance reserves of coal were $1.69 \mathrm{~m}$ thick, a layer of mixed shale and sandy shale was $5.06 \mathrm{~m}$ thick, and a layer of sandstone was $1.68 \mathrm{~m}$ thick. The direct roof rocks were composed of shales and sandy shales, and a layer of sandstone was deposited above them. In the aforementioned geological profile (Fig. 1a), the following layers of roof rock sequence were present: a layer of mixed shale and sandy shale ( $0.17 \mathrm{~m}$ thick), a layer of sandstone (3.61 m thick), a layer of mixed shale and sandy shale (17.58 $\mathrm{m}$ thick) and then the next coal seam, no. 407/3 (2.77 m thick). Coal seam no. 407/3 is deposited approximately $24 \mathrm{~m}$ above coal seam no. 408 (Fig. 1a). This coal seam was not extracted over coal seam no. 408's longwall panel. Only one longwall panel was mined to the north of the study area, approximately $3-$ 4 years earlier.

The next coal seam, no. 405/2, deposited approximately $106 \mathrm{~m}$ above coal seam no. 408 (Fig. 1a), was divided into layers due to its relatively high level of thickness of $7.4 \mathrm{~m}$. The upper part of coal seam no. 405/2 (405/2tl) was mined approximately 17 to 19 years earlier and in a wider area. Only close to the beginning and the end of the studied longwall panel was the edge of coal seam no. 405/2tl present. Over most of the studied longwall panel, coal seam no. 405/2tl was mined in the past, and the edge of this coal seam was present approximately $120 \mathrm{~m}$ to the south. The extraction of the lower part of coal seam no. 405/2 (405/2bl) was conducted approximately 4 to 11 years earlier but over a 

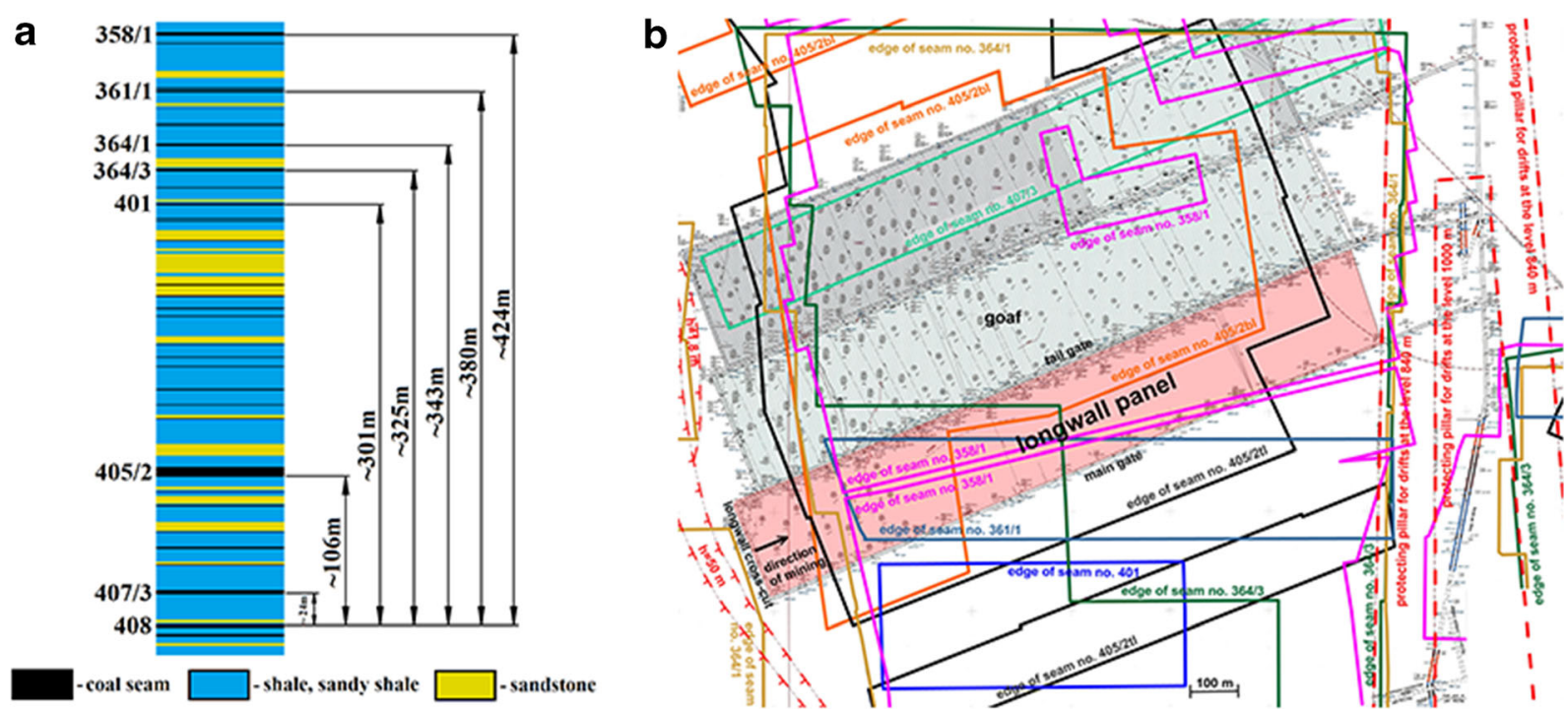

Fig. 1 Geological profile captured from the borehole drilled within the studied longwall panel (a) and map of coal seam no. 408 with the edges of overlaying coal seams (b)

smaller area. The edge of this coal seam was present across most of the studied longwall panel.

Coal seam no. 401 with a thickness of $1.2 \mathrm{~m}$ and deposited approximately $301 \mathrm{~m}$ above coal seam no. 408 (Fig. 1a) was not extracted directly over the selected longwall panel. Some extraction of this coal seam was performed to the south approximately 3 to 4 years earlier, but, due to irregular deposition, it was abandoned. Moreover, a group of sandstone layers was located $17 \mathrm{~m}$ below coal seam no. 401 (Fig. 1a). The total thickness of these sandstone layers was approximately $36 \mathrm{~m}$ and this group was interbedded with four layers of other gangue (shale and sandy shale with thickness of $1.35 \mathrm{~m}, 1.4 \mathrm{~m}$ and $5.09 \mathrm{~m}$, and conglomerate with thickness of $2.21 \mathrm{~m}$ ) and two thin coal seams $(0.4 \mathrm{~m}$ and $0.46 \mathrm{~m})$.

Incomplete extraction of coal seams nos. 364/3, 364/ 1, 361/1 and 358/1 (Fig. 1b) was carried out in the past at far vertical distances from coal seam no. 408. These extractions took place at least 13 years before extraction of coal seam no. 408 began. Coal seam no. 364/3 with the thickness of $2.25 \mathrm{~m}$, deposited approximately $325 \mathrm{~m}$ above coal seam no. 408 (Fig. 1a), was not mined totally over the selected longwall panel. The edge of this coal seam covered the middle of the studied longwall panel (Fig. 1b). The edge of this coal seam was also present at the end of the selected longwall panel (Fig. 1b). The next coal seam no. $364 / 1$ with the thickness of $1.6 \mathrm{~m}$ and deposited approximately $343 \mathrm{~m}$ above coal seam no. 408 (Fig. 1a) was almost completely mined. The edge of coal seam no. $364 / 1$ was present at the beginning and the end of the studied longwall panel (Fig. 1b). The next coal seam no. 361/1 was partly mined over the selected longwall panel (Fig. 1b). In this part of the deposit, only one longwall panel in coal seam no. 361/1 was mined. The distance between coal seams nos. 408 and 361/1 was approximately $380 \mathrm{~m}$ (Fig. 1a). The thickness of coal seam no. 361/1 was approximately $1 \mathrm{~m}$, and it was allied with other narrow coal seams with thicknesses of $0.2 \mathrm{~m}$ and $0.45 \mathrm{~m}$, ribbed by thin layers of shales (both $0.2 \mathrm{~m}$ ). The edge of coal seam no. 361/1 was present above the western part of the studied longwall panel. In the eastern part of the deposit, this edge was located to the south of the selected longwall panel (Fig. 1b). At the distance of approximately $424 \mathrm{~m}$ from coal seam no. 408, coal seam no. 358/1 was deposited (Fig. 1a). The thickness of this coal seam reached $2.1 \mathrm{~m}$, and its extraction was almost completed. Coal seam no. 358/ 1 's edge was also present above the beginning and the end of the studied longwall panel. Moreover, in the past, approximately a $15-\mathrm{m}$-wide rib of coal seam no. 358/1 remained above most of the studied longwall panel. In the eastern part of the deposit, it was present to the south of the selected longwall panel (Fig. 1b).

Edges of far-distant coal seams 358/1, 364/1 and 364/ 3 were present above the eastern part of the studied longwall panel. The location of these edges correlated well with the border of the protecting pillar for drifts at the level of $840 \mathrm{~m}$. The stress-strain equilibrium in the 
vicinity of the protecting pillar was highly uneven. The stress level increased closer to the border of the pillar. Extraction of coal seam no. 408 was planned to end at the border of this pillar, which was economically viable. However, activation of geomechanical processes near the protecting pillar could not be ruled out.

\section{Seismic monitoring and seismic activity}

The analysed longwall panel was monitored by the mine seismic network, comprised of vertical component sensors including both seismometers and geophone probes. This network included 13 seismic stations, located in underground openings at a depth of between $640 \mathrm{~m}$ and $1050 \mathrm{~m}$ b.g.l. The ground level is about $250 \mathrm{~m}$ above the sea level. The location of the tremor foci was obtained using the P wave first arrivals method. The error of epicentral location in the longwall panel and its vicinity was in the range of between less than $30 \mathrm{~m}$ to a maximum of approximately $120 \mathrm{~m}$. Due to the configuration of the seismic sensors (Fig. 2a), the lowest values of epicentral location error was in the east, at the end of the longwall panel (Fig. 2b). The error of vertical coordinate $\mathrm{Z}$ ranged from approximately 60 to $200 \mathrm{~m}$, assuming $\mathrm{P}$ wave first arrival time error of $10 \mathrm{~ms}$ and velocity model error of $20 \mathrm{~m} / \mathrm{s}$.

The seismic energy $E$ of the observed tremors was calculated using the method of the numerical integration of seismograms. The simplified form of the used formula is presented below (Wojtecki and Gołda 2019):

$E=2 \pi r_{i}^{2} \rho v_{i} \frac{1}{k_{i}^{2}} f e^{b} d_{i} \sum_{n} A_{i, n}^{2}$

For each of the seismic station $i$, the square of the amplitude $A_{i}$ between the start and end markers and in the $n$ following samples, the sampling rate $f(500 \mathrm{~Hz})$, the density of the rock mass $\rho\left(2600 \mathrm{~kg} / \mathrm{m}^{3}\right)$, the attenuation of the rock mass - quality factor (Wojtecki and Gołda 2019) - which reciprocal is present in factor $b$, the calibration factor $k_{i}$ of the seismic sensor, the distance between the focus and the seismic station $r_{i}$, the depth factor $d_{i}$ and the seismic wave velocity $v_{i}(3800$ $4100 \mathrm{~m} / \mathrm{s}$ ) were the parameters for the calculation of the seismic energy. The parameter $e$ included in the mentioned formula is the base of natural algorithms. The energies of all the seismic stations were arithmetically averaged providing the seismic energy $E$ of each tremor (Wojtecki and Gołda 2019). The seismic energy of mining tremors was calculated in an analogous manner. The energy of strong tremors was verified with the calculations of the Upper Silesian Regional Seismological Network which belongs to the Central Mining Institute in Katowice, Poland. This network was established in 1974, and it has been successively developed (Stec and Lurka 2015). The Upper Silesian Regional Seismological Network is an overarching
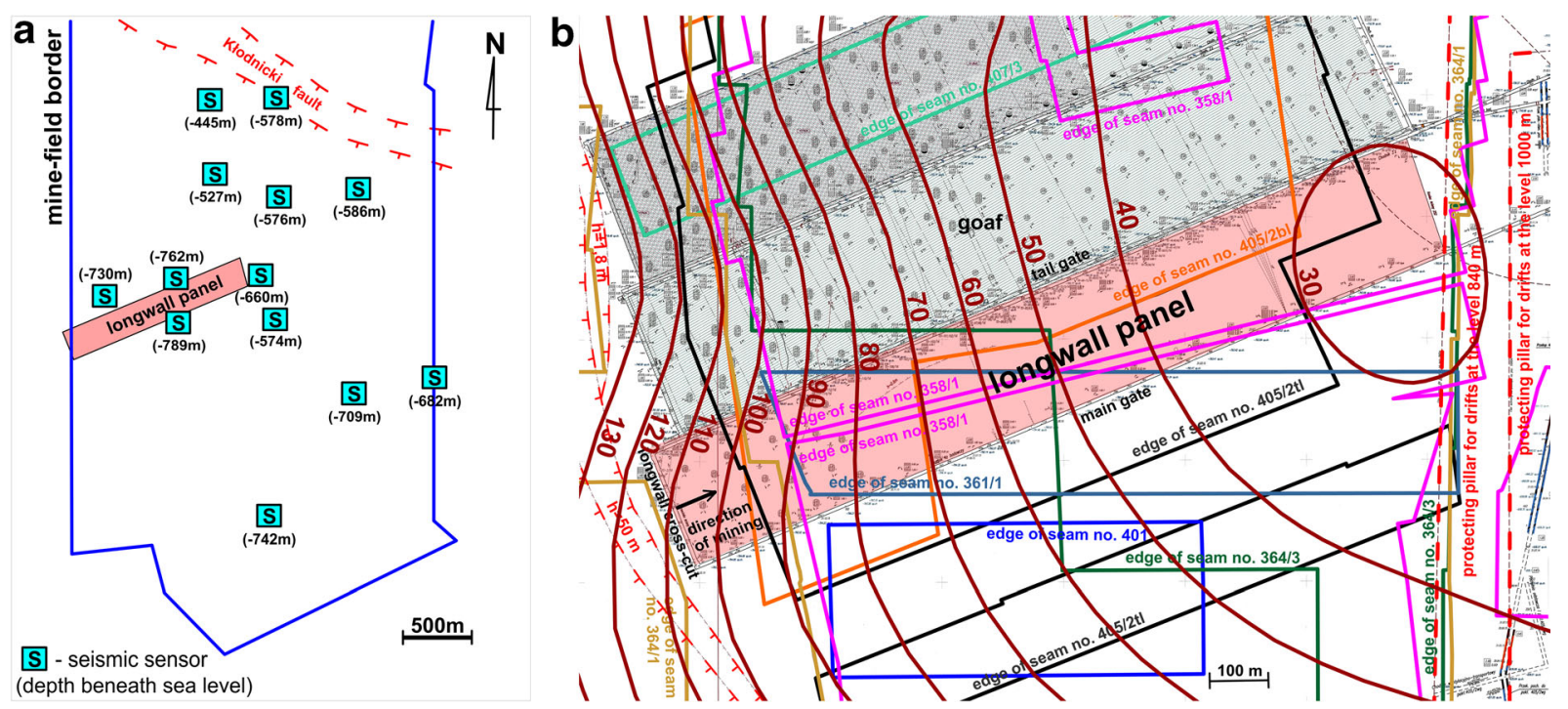

Fig. 2 Configuration of seismic sensors (a) and a map of coal seam no. 408 with the monitored longwall panel and isolines of epicentral location error, in $[\mathrm{m}](\mathbf{b})$ 
network, relative to the local seismic networks operating separately in hard coal mines of the Upper Silesian Coal Basin. The network contains three types of seismometers: Willmore MKIII, GeoSIG sensors and rotational seismometers.

The extraction of coal in the studied longwall panel caused an increase in the seismicity in the panel and its vicinity. In total, 1152 mining tremors were classified as been directly caused by the longwall panel, according to the criterion of the distance between the epicentre and longwall face $(<200 \mathrm{~m}$ plus error of the epicentral location). The total energy of these tremors was $2.43 \cdot 10^{8} \mathrm{~J}$. The energies were converted to local magnitude $M_{L}$ which was calculated according to the formula $\log E=1.8+1.9 M_{L}$ introduced by Dubiński and Wierzchowska (1973). The observed tremors were divided into three groups according to their energies: low-, medium-, and high-energy. Six hundred fourteen lowenergy tremors were recorded with energy of $10^{2} \mathrm{~J}$ $\left(0.11 \leq M_{L}<0.63\right)$ and 229 with energy of $10^{3} \mathrm{~J}$ $\left(0.63 \leq M_{L}<1.16\right)$. In total, 199 medium-energy tremors were observed, i.e. with energy of $10^{4} \mathrm{~J}$ $\left(1.16 \leq M_{L}<1.68\right)$. However, 101 were provoked by blasting of roof rocks. Seventy-eight high-energy tremors with energy of $10^{5} \mathrm{~J}\left(1.68 \leq M_{L}<2.21\right)$ and 31 with energy of $10^{6} \mathrm{~J}\left(2.21 \leq M_{L}<2.74\right)$ were recorded, and these were found especially in the southern and south-eastern part of the longwall panel and outside of it (Fig. 3). In addition to these seismic events, one very strong event occurred. Its seismic energy reached $1 \cdot 10^{8} \mathrm{~J}\left(M_{L}=3.26\right)$, and its epicentre was at the border of the protecting pillar. This zone is covered by the cluster of far-distant coal seams edges (nos. 358/1, 364/1 and 364/3).

Moreover, the epicentres of 251 tremors occurred at a distance greater than $200 \mathrm{~m}$ from the longwall face which resulted in the increase of epicentral location error. These events were classified as follows: 209 low-energy (140 of $10^{2} \mathrm{~J}$ and 69 of $\left.10^{3} \mathrm{~J}\right), 31$ medium-energy and 11 high-energy ( 9 of $10^{5} \mathrm{~J}$ and 2 of $\left.10^{6} \mathrm{~J}\right)$. However, it cannot be ruled out that the extraction of coal indirectly influenced their occurrence.

The seismic activity associated with the excavation varied from low to high level. None of the high-energy tremors occurred at the beginning of the longwall panel, even if they were above the edges of coal seams nos.

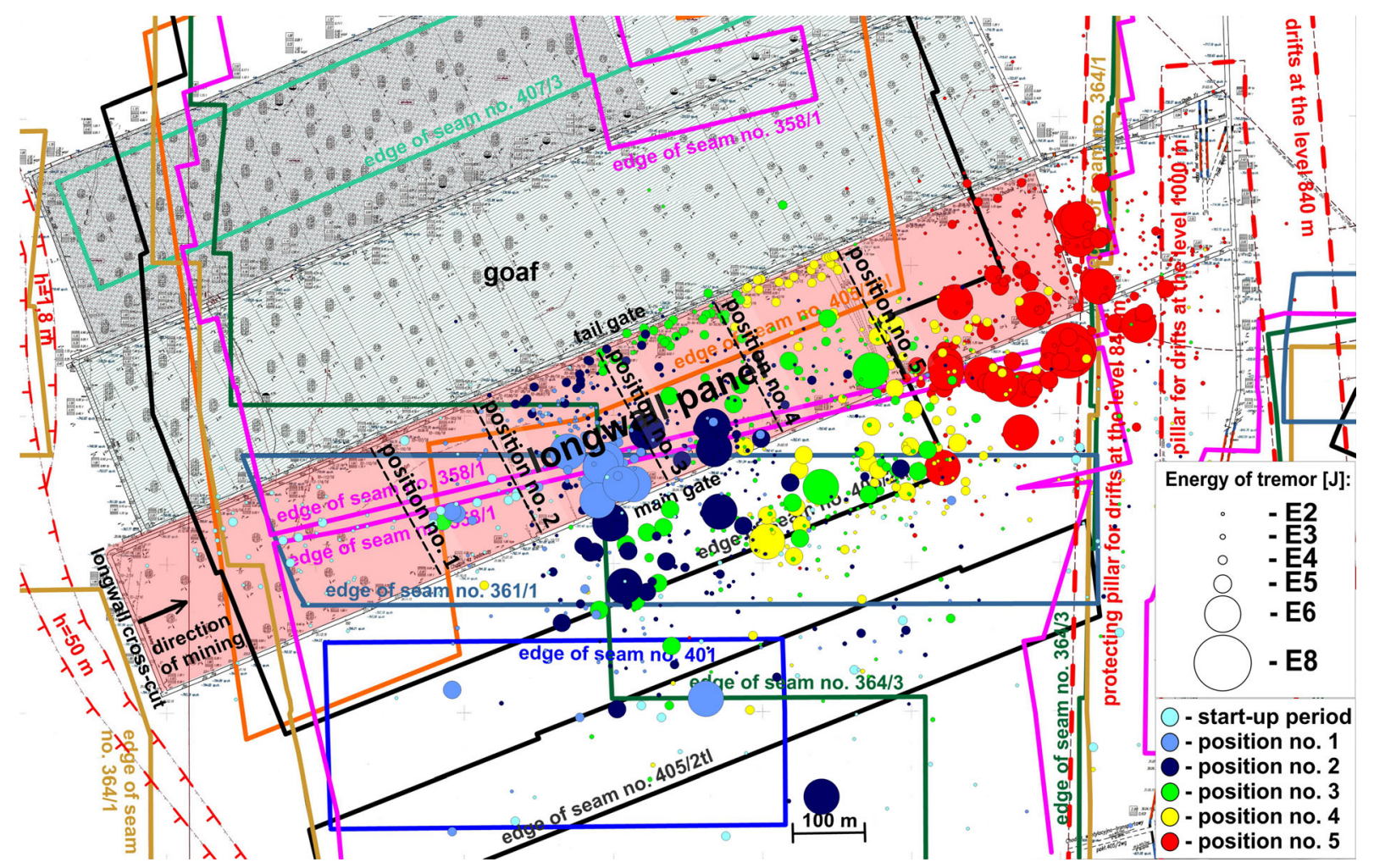

Fig. 3 Total seismic activity during the extraction of coal seam no. 408's longwall panel 
405/2bl, 405/2tl, 364/1, 361/1 and 358/1 (Fig. 3, start-up period). Probably fracturing of the main roof rocks had at the time not yet developed. Strong tremors did not occur also when the longwall face was under the goaf made by the previous extraction of thick coal seam no. $405 / 2$. The extraction of this seam successfully destressed the rock mass in this area.

The first two strong tremors, both with energy of $5 \cdot 10^{5} \mathrm{~J}\left(M_{L}=2.05\right)$, occurred in the central part of the longwall panel, in the vicinity of the edge of the lower panel of coal seam no. 405/2 (no. 405/2bl), on the 223rd and 232nd day of longwall mining, respectively. These tremors occurred when the longwall face advance almost reached the edge of 405/2bl along the main gate (Fig. 3, longwall face position no. 1). Three days after the last strong tremor (the 235th day of longwall mining), a series of 7 strong tremors, mostly with energy of $10^{6} \mathrm{~J}$, began. In this sequence, the strongest event released seismic energy of $9 \cdot 10^{6} \mathrm{~J}\left(M_{L}=2.71\right)$, and the weakest was $6 \cdot 10^{5} \mathrm{~J}\left(M_{L}=2.09\right)$. The time interval between these mining tremors ranged from 4 to 6 days (4.8 days average). Their epicentres coincided with the edges of coal seams nos. 364/3, 361/1 and 358/1, and their foci were located close to each other, from approximately 200 to $130 \mathrm{~m}$ ahead of the longwall face. During this sequence, the longwall face systematically approached the edges of these far-distant coal seams. This series ended on the 260th day of longwall mining.

The second series of 19 strong tremors occurred approximately 17 days later, i.e. from the 277 th day of longwall mining (Fig. 3, longwall face position no. 2 ). The time interval in this sequence varied between from 1 to 7 days (average 3.5 days). The epicentres were mainly located to the south and east of the edges of the far-distant coal seams nos. 364/3, 361/1 and $358 / 1$. Eleven of them ( 8 of energy $10^{5} \mathrm{~J}$ and 3 of energy $10^{6} \mathrm{~J}$ ) were located along the edge of coal seam no. $364 / 3$, to the south of the studied longwall panel, and they extended up to the edge of coal seam no. 405/2tl (Fig. 3, longwall face position no. 2). The epicentres of the next 6 strong tremors ( 3 of energy $10^{5} \mathrm{~J}$ and 3 of energy $10^{6} \mathrm{~J}$ ) were located to the east of the far-distant coal seam no. 364/3 within the studied longwall panel and spread along the edges of far-distant coal seams nos. 361/1 and 358/1. One tremor with energy $10^{5} \mathrm{~J}$ and another with energy of $10^{6} \mathrm{~J}$ were located to the south of the longwall panel, close to the edge of coal seam no. 405/2tl. During this sequence, the longwall face methodically approached the crossing of edges of coal seams nos. 364/3, 361/1 and $358 / 1$. The last strong tremor in this series took place on the 339th day of longwall mining.

After 13 days, the third series of strong tremors occurred, i.e. on the 352nd day of longwall mining (Fig. 3, longwall face position no. 3). During this period, the longwall face was in the part of rock mass where coal seam no. 405/2tl was mined, and it systematically proceeded to the east. In this sequence, tremors with seismic energy of $10^{5} \mathrm{~J}$ dominated. Of the 19 strong tremors, only two had energy of the order of $10^{6} \mathrm{~J}$. Unlike the previous series, the distribution of the tremor epicentres became more irregular. Epicentres of 6 tremors with energy of $10^{5} \mathrm{~J}$ were located within the longwall panel, below the edge of the lower part of coal seam no. $405 / 2$ (no. 405/2bl). The epicentres of 8 tremors with energy of $10^{5} \mathrm{~J}$ were located to the south of the studied longwall panel, near the edges of coal seams nos. $364 / 3$ and 405/2tl. The epicentres of two tremors with energy of $10^{6} \mathrm{~J}$ and three with energy of $10^{5} \mathrm{~J}$ were located inside and outside of the longwall panel, below the edge of coal seam no. 405/2tl. The average time interval between tremors in this series varied from 1 to 7 days (4 days average). The last strong tremor in this series was on the 422nd day of longwall mining.

Seventeen days later, i.e. on the 439th day of longwall mining, a fourth sequence started (Fig. 3, longwall face position no. 4). During this series, the longwall face was still in the part of rock mass where coal seam no. 405/2tl was mined, but at the end of this series, the longwall face was just in front of the edge of this coal seam. This series was composed of 19 strong tremors. Only one tremor with energy of the order of $10^{6} \mathrm{~J}$ occurred. The other tremors released seismic energy of $10^{5} \mathrm{~J}$. The epicentres, including the strongest one, were mainly located to the south of the studied longwall panel, below the edge of coal seam no. 405/2tl. Some of them were located not far from this edge, close to the longwall panel and near the edges of far-distant coal seams nos. 358/1 and 361/1. The epicentres of two strong tremors were located within the longwall panel and below the edge of coal seam no. 405/2tl. The time interval varied between the mining tremors from 1 to 7 days (average 3.5 days). The last strong tremor in this series was on the 502nd day of longwall mining.

The last sequence of high-energy tremors started 27 days later, i.e. on 529th day of longwall mining (Fig. 5, longwall face position no. 5). At the beginning of this sequence, the longwall face started to run under 
the edge of coal seam no. 405/2tl. During this period, the longwall face steadily approached the border of the protecting pillar disturbing the stress-strain equilibrium at its border. The stress-strain equilibrium in this zone was affected by the edges of far-distant coal seams which was reflected in the observed seismicity level. In total, 44 strong tremors occurred during this period, 28 released seismic energies of the order of $10^{5} \mathrm{~J}, 15$ with seismic energy of the order of $10^{6} \mathrm{~J}$, as well as, the strongest tremor in the entire seismic catalogue, i.e. the event with energy of $1 \cdot 10^{8} \mathrm{~J}\left(M_{L}=3.26\right)$. The time interval between them ranged from just seconds to 11 days (3.7 days average). During the last period, the epicentres of four tremors with seismic energy of $10^{5} \mathrm{~J}$ and two with seismic energy of $10^{6} \mathrm{~J}$ were located below the edge of coal seam no. 405/2tl. However, most of the epicentres during this time, including the strongest tremor, were located to the south of the studied longwall panel, near the edges of far-distant coal seams nos. 358/ 1 and 361/1 and at the border of the pillar where edges of far-distant coal seams nos. 358/1, 364/1 and 364/3 were present as well (Fig. 3). The epicentre of the tremor with the energy of $1 \cdot 10^{8} \mathrm{~J}$ was located in the vicinity of these three edges (Fig. 3). The epicentres of other strong tremors were located to the east of the end of the studied longwall panel, at the border of the pillar.

To summarize, the epicentres of the high-energy tremors were mainly located in the southern part of the studied longwall panel or to the south and east of it. The edges of coal seam no. 405/2 and far-distant coal seams, $358 / 1,361 / 1,364 / 1$ and 364/3, were present in this area. No strong tremors occurred in the northern part, i.e. in the zone where earlier extraction of coal seam no. 405/2 had been fully completed. Therefore, it can be assumed that the destressed effect was still present there. The highest seismicity was observed when the longwall panel approached the zone under the influence of the border of the pillar, where the edges of the far-distant coal seams were present. The error of the epicentral location in the zone where the strongest tremors occurred was at a level of approximately $30-50 \mathrm{~m}$. Therefore, the correct location of strong tremor epicentres can be assumed.

\section{Distributions of the energy and frequency of mining tremors}

As previously mentioned, geomechanical processes are responsible for mining tremor occurrence (Stec 2015;
Dubiński et al. 2019; Wojtecki et al. 2019). Strong mining tremors are precisely correlated with the geological and mining factors which are present in hard coal mines, e.g. layers of competent rocks, faults, edges of coal seams and pillars. According to the distributions of the energy and frequency of tremors, it is possible to determine the most probable causes of their occurrence. Some of the causes considered can then be ruled out.

The 2D distribution of the seismic energy of strong tremors within the studied longwall panel and out of it is shown in Fig. 4. The area was divided into cells of equal dimension, i.e. $50 \times 50 \mathrm{~m}$. The seismic energy of tremors in each cell was added together. The isolines' connecting points with identical seismic energy values were generated using the kriging interpolation method. The areas where most of the seismic energy was released from were located in the middle of the selected longwall panel and at the end of the longwall panel, close to the border of the protecting pillar. In both cases, the edges of far-distant coal seams coexisted there (Fig. 4), and no other factor which might be responsible for strong mining tremor occurrence was present.

The seismic energy was also released to a greater degree from the vicinity of the edge of the upper part of coal seam no. 405/2, located mostly to the south of the studied longwall panel. Similarly, the seismic energy was released from the vicinity of the edge of the lower part of coal seam no. 405/2 situated over the central part of the studied longwall panel as well.

The distributions of the frequency of strong tremors and their energies as a function of distance from the border of the protecting pillar are shown in Fig. 5. Two maxima can be clearly distinguished from both of the distributions presented. The first maximum is placed at the distance corresponding to the zone of the three edges of the far-distant coal seams nos. 358/1, 361/1 and 364/3 which covers the central part of longwall panel, i.e. at the distance of approximately $620 \mathrm{~m}$ from the border of the pillar for drifts at the level of $840 \mathrm{~m}$, in the western direction (Fig. 5). The second maximum is placed directly at the border of the pillar. This maximum is extended by up to approximately $50 \mathrm{~m}$ in the western direction, i.e. in the direction of extracted coal seams nos. 358/1, 364/1 and 364/3. These distributions show that when the vicinity of the edges of distant coal seams coexist together, the processes of rock mass destruction were particularly intense.

The distributions of the frequency of strong tremors and their energies as a function of distance from the 


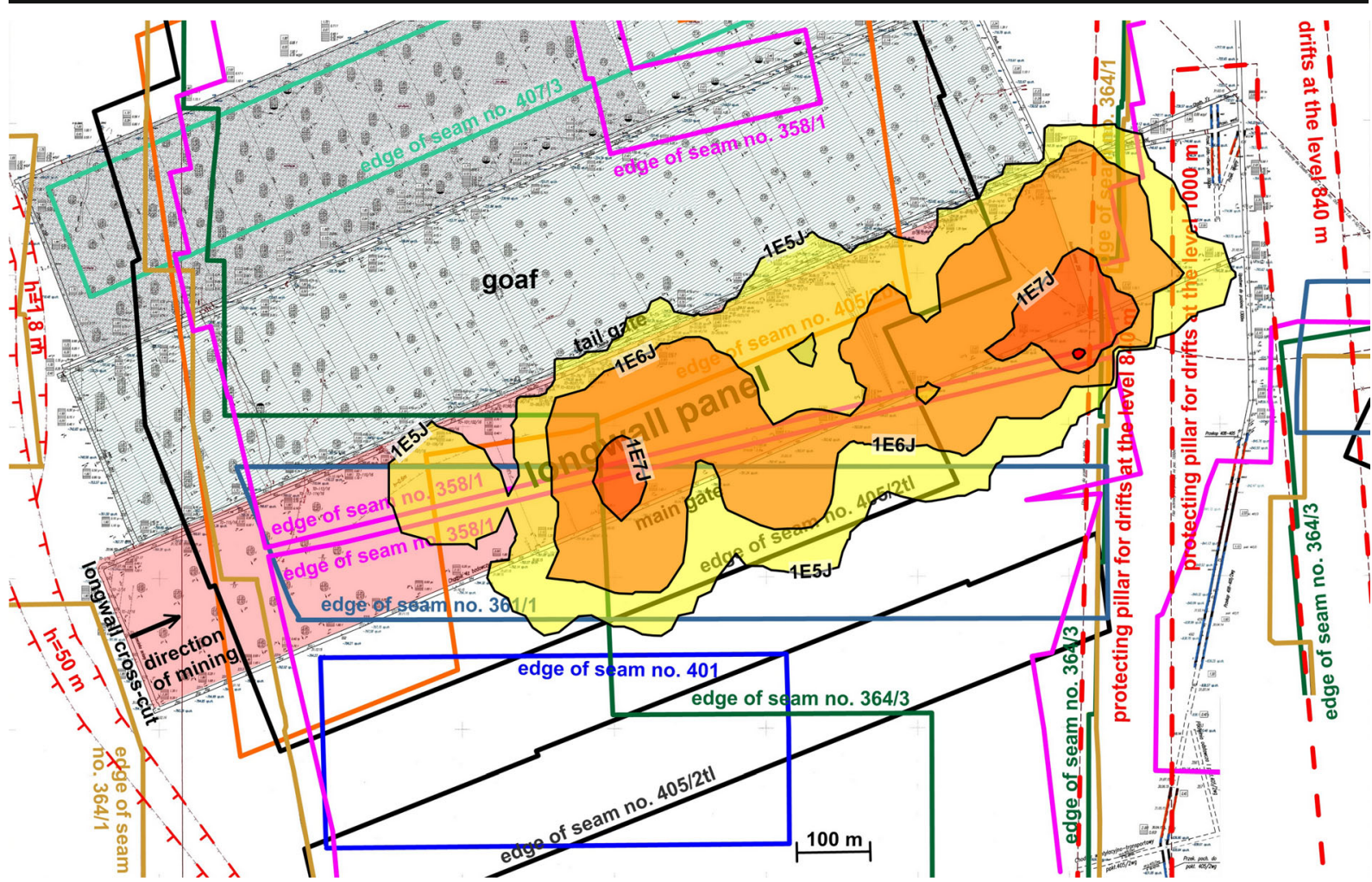

Fig. 4 The seismic energy distribution in the area of the studied longwall panel

longwall face were determined (Fig. 6). The negative distances in Fig. 6 represent tremors from the side of goaf, and positive distances correspond to tremors from the side of the unmined coal. These distributions were prepared for all strong tremors and those whose epicentres were located only within coal seam no. 408's longwall panel. By analysing the distributions, it can be found that a large number of strong tremors took place outside of coal seam no. 408's longwall panel. A maximum can be clearly distinguished in the distribution of the frequency of strong tremors (Fig. 6, right). Most of the tremors occurred approximately $70 \mathrm{~m}$ from the side of the unmined coal. A large amount of the seismic energy was released outside of the longwall panel too. Two maxima can be clearly distinguished in the distribution of the seismic energy of strong tremors
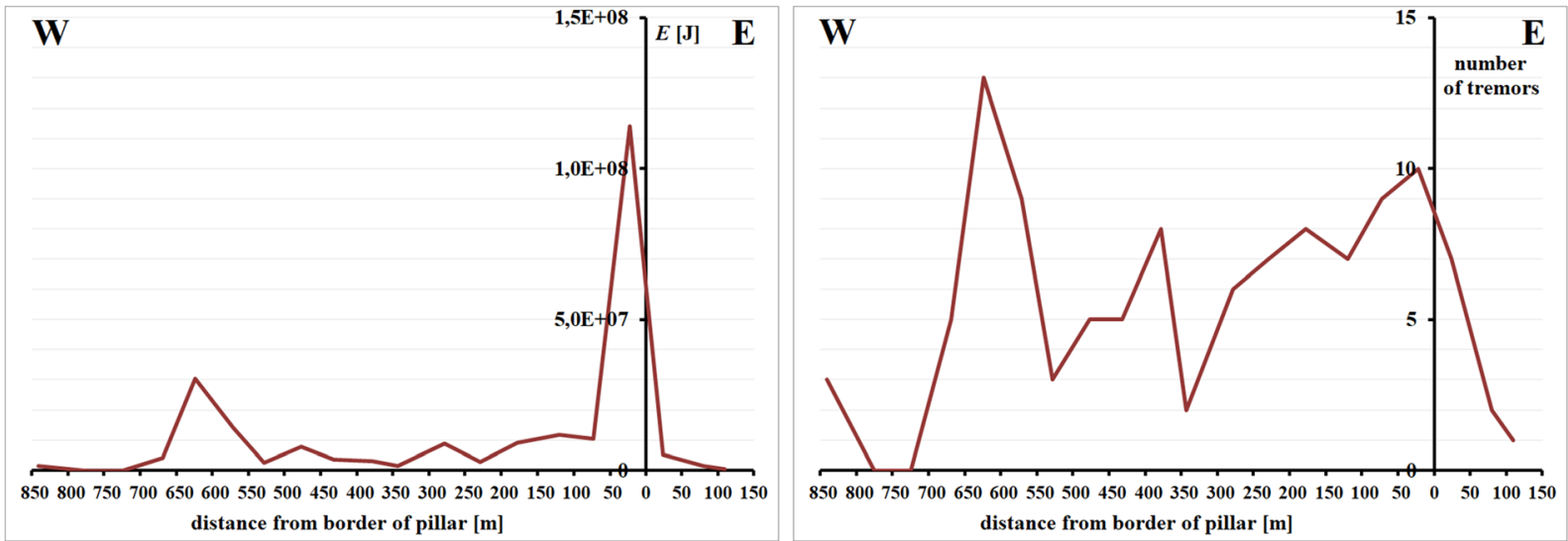

Fig. 5 The distributions of the seismic energy (at left) and the frequency of strong tremors (at right) as a function of the distance from the border of the pillar for drifts at the level of $840 \mathrm{~m}$ 


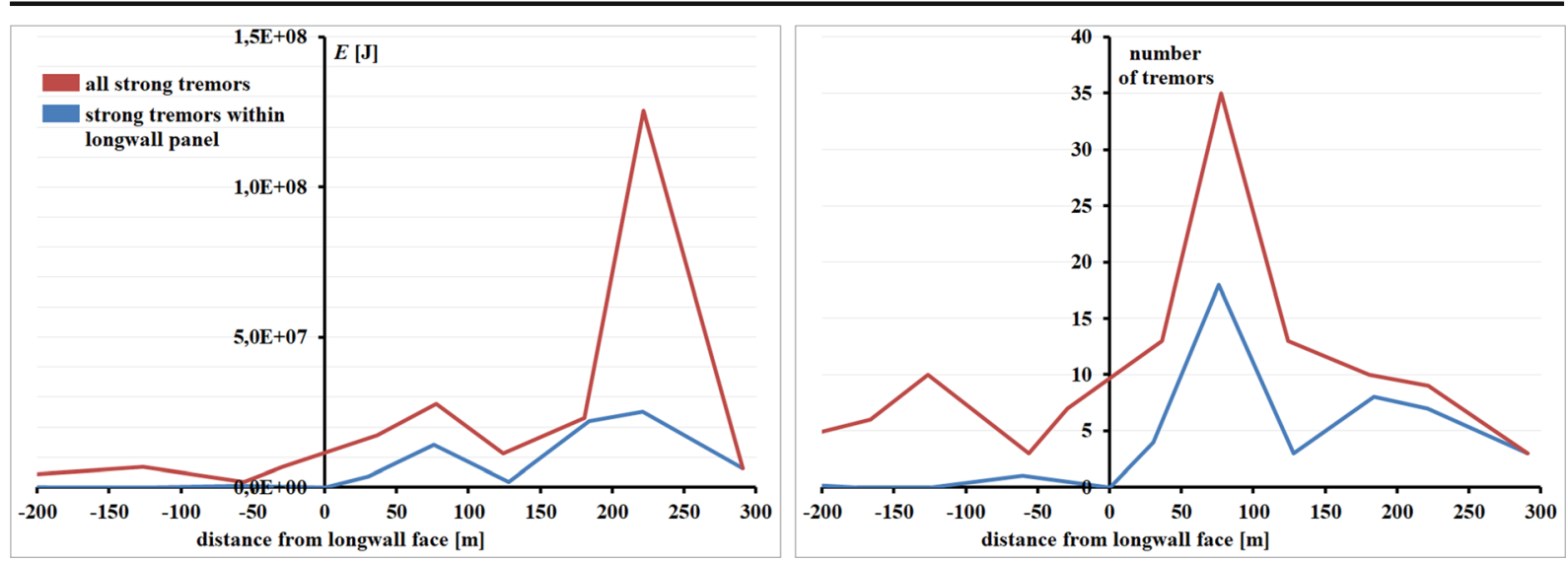

Fig. 6 The distributions of the seismic energy (left) and frequency of strong tremors (right) as a function of the distance from the longwall face

(Fig. 6, left). A minor one is present at approximately $70 \mathrm{~m}$, and a major one occurs approximately $220 \mathrm{~m}$ from the side of the unmined coal. The longwall mining of coal seam no. 408 affected the highly uneven stressstrain distribution occurring in this part of the mining area, established by the earlier extraction of coal seam no. 405/2 and the far-distant coal seams.

\section{Seismic hazard}

Spatial and temporal seismicity rate anomalies are essentially reported as the most frequent intermediate-term precursory phenomenon in timescales varying from a few days to several years (Leptokaropoulos et al. 2017). Recent studies focused on two approaches: parametric and non-parametric. The first approach is based on the use of the well-established Gutenberg-Richter law which was applied in many pieces of research on seismic hazard in mines (e.g. Lasocki 1994; Lasocki 1995; Gołda and Kornowski 2011a, 2011b; Convertito et al. 2012; Mutke et al. 2015; Leptokaropoulos et al. 2017). The non-parametric hazard assessment approach is evaluated under certain conditions (e.g. Kijko et al. 2001; Lasocki and Orlecka-Sikora 2008). In this study, the parametric approach was applied. The parameters required to estimate the seismic hazard during mining in the studied mine were calculated based on Pareto's distribution (Lasocki 1995):

$F(E)= \begin{cases}1-\left(E_{0} / E\right)^{b} & E \geq E_{0} \\ 0 & E \leq E_{0}\end{cases}$ where $E$ is the considered energy from the catalogue, $E_{0}$ is the certain minimum energy, and $b$ is the Gutenberg-Richer parameter. The analysis of the seismic catalogue from the studied longwall panel indicated that the minimum energy is $500 \mathrm{~J}$. In this study, it was assumed that the minimum energy corresponds to the energy with the largest frequency of seismic events in the low-energy range. The $b$ value was estimated as follows (Lasocki 1995):

$b=n\left[\sum_{i=1}^{n} \ln \left(E_{i} / E_{0}\right)\right]^{-1}$

where $n$ represents the consecutive events in the time intervals. In this case, 10-day intervals were chosen. The used probability distribution of energy cut the catalogue in the low-energy part, but an upper limit was not included. Figure 7 shows the estimation of the $b$-values per 10-day interval. The $b$-value uncertainty is calculated from ratio of $b$ estimator and square root of the number of events in the interval (Gołda and Kornowski 2011a). The analysed area had time intervals with an extremely low frequency of events. Therefore, the proposed estimation of $b$-value is treated as a good approximation of changes in the seismicity characteristics. It was arbitrarily assumed that $b$ was calculated according to Eq. (3) for the event frequency exceeding 5. In other cases, $b$ was assumed as 0 .

It is clearly shown that the $b$-values decreased before crossing the longwall face below the cluster of seam edges of 358/1,361/1 and 364/3. Furthermore, the level of $b$-values is low and reaches average value of 0.5 . 


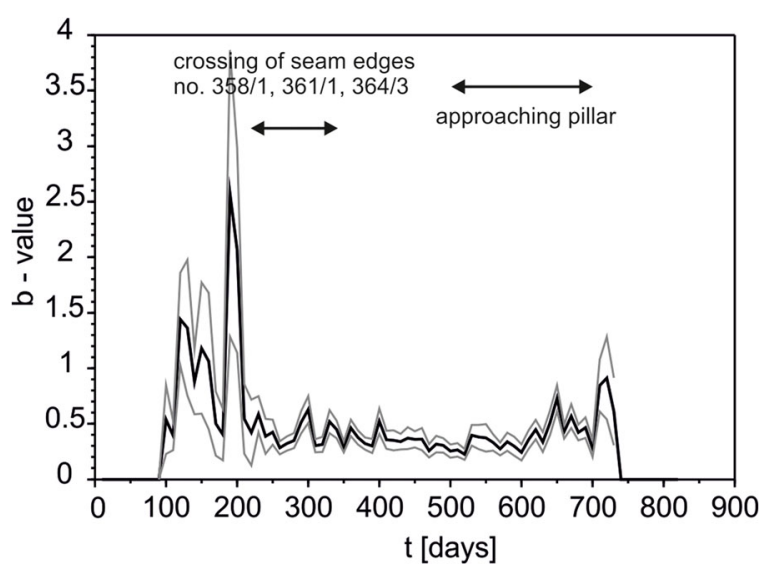

Fig. 7 The estimations of $b$-value per 10-day interval. Black solid line, estimation; grey solid line, standard deviation intervals

When the mining was terminated and the longwall approached the protection pillar, the $b$-values slightly increased. Moreover, the pillar zone was affected by the presence of far-distant coal seams nos. 358/1, 361/1, $364 / 1$ and $364 / 3$. The higher $b$-value indicates that the low-energy events dominate in the energy-frequency distribution causing the larger inclination of the distribution. The increase in the number of high-energy tremors results in a reduction of the distribution slope.

Maximum probability distribution was calculated based on the known energy distribution and the assumption that the event frequency distribution in a short or long period is the Poisson distribution. Thus, the cumulative probability distribution function of the maximum energy event can be expressed as follows (Lasocki 1994; Lasocki 1995):

$G\left(E^{\max }\right)=\frac{e^{-\lambda \Delta t(1-F(E))}-e^{-\lambda \Delta t}}{1-e^{-\lambda \Delta t}}$

where $\lambda$ is the event frequency per time (the Poisson factor) and $\Delta t$ is time interval width. The empirical cumulative distribution function was estimated based on the equation (Lasocki 1995):

$G_{\text {emp }}\left(E^{\max }\right)=\frac{i-0.5}{w}$

where $i$ is the number of maximum energy events in the interval and $w$ is the interval.

The estimated $b$-values and energy distribution $F(E)$ enabled the calculation of the cumulative probability distribution function of the maximum energy for the entire seismic catalogue (Fig. 8a) and its comparison with the empirical distribution. The visual inspection enabled a satisfactory comparison of both distribution and convinced us to use this data to estimate the probability of the occurrence of an event of a certain energy or larger during the selected time interval. This calculation requires two assumptions. Firstly, the analysed process is stationary for a small interval; thus, 10-day intervals were chosen, and secondly, the intervals contain a sufficient number of events. This second condition is difficult to fulfil; however, in the studied case, the minimum number of events in a 10-day interval reached 5 , the maximum was 46 , and the average was 16.9 . The probability of exceeding a certain amount of energy $E$ can be estimated as follows (Lasocki 1995):

$R(E, t)=\left(1-e^{-\lambda(t) \Delta t}\right) \cdot(1-F(E, t))$

where the Poisson factor and the energy distribution vary with time.

The results of the exceedance probability calculated for the energy of $5 \cdot 10^{5} \mathrm{~J}$ per 10 day period are shown in Fig. $8 \mathrm{~b}-\mathrm{d}$. Next, the probability was compared with the total seismic energy released in the 10-day intervals (Fig. 8b), the event frequency per 10-day interval $(\lambda)$ (Fig. 8c) and the 10-day moving average of energy released (Fig. 8d).

This summary indicates that the highest probability of exceedance was associated with mining carried out near the protection pillar, where old far-distant edges occurred. Two maxima with $18 \%$ probability of exceeding the high-energy tremor can be found (Fig. 8b). However, a lower probability was noticed for the period associated with the crossing of the longwall face below the seam edges of 358/1,361/1 and 364/3. There are three main peaks with $9 \%$ probability of exceedance, but this period, in contrast to the period of the pillar approach, was characterized by higher seismicity (Fig. $8 b-d)$. Nevertheless, the probability in the period of the face crossing below the seam edges of 358/1,361/1 and $364 / 3$ is still higher than in the other time intervals. This suggests that the far-distant edges caused an increase in seismicity and the level of seismic and rockburst hazard. Moreover, during the period of 650 day-700 day, the decrease in the probability of exceedance is noticeable. It was caused by the increase in low-energy seismicity (Fig. 8c) with a relatively small number of the strong events $\left(>10^{5} \mathrm{~J}\right)$ which according to the Eq. (6) resulted in the drop of seismic hazard during this specific period. The other parameters remained at a similar level, i.e. $b$ - 

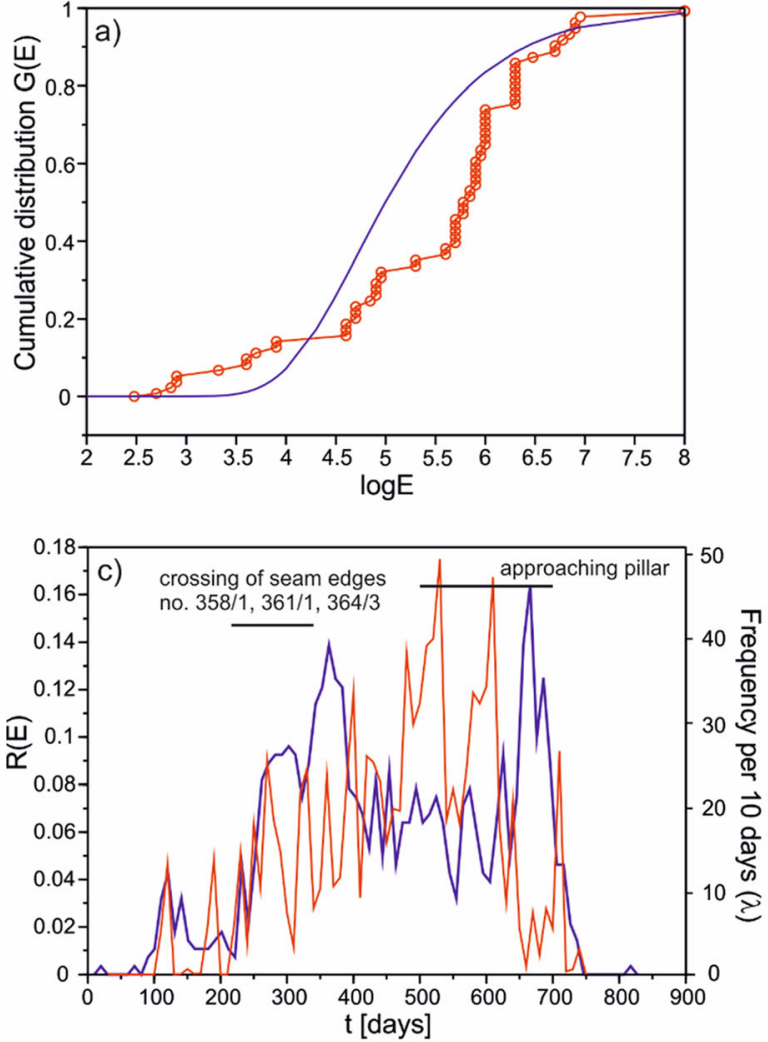

Fig. 8 The seismic hazard assessment results: (a) comparison of the cumulative probability distribution function of the maximum energy (blue line) and empirical cumulative distribution (red line); (b) the probability of the occurrence of an event with energy of $>$ $5 \cdot 10^{5} \mathrm{~J}$ per 10-day interval (red line) and the cumulated energy released during 10-day intervals; $(\mathbf{c})$ the probability of the

value and corresponding the value of the Pareto's distribution $F(E, t)$.

\section{Seismic energy release-BENIOFF plot}

In order to analyse the characteristics of seismic energy release during the mining operation, the Benioff strain was calculated (Fig. 9a). The Benioff strain is defined as the root square of the seismic energy and presented as a cumulative plot (Mendecki et al. 2019). The cumulative Benioff strain release (BSR) models enable the approximation of the behaviour of the stress regime in the rock masses surrounding longwall fields, and they can be used to better understand the processes occurring during underground exploitation (Mendecki et al. 2019). The BSR models (or similar using seismic moment or energy) originated from the work of Voight (1989), which
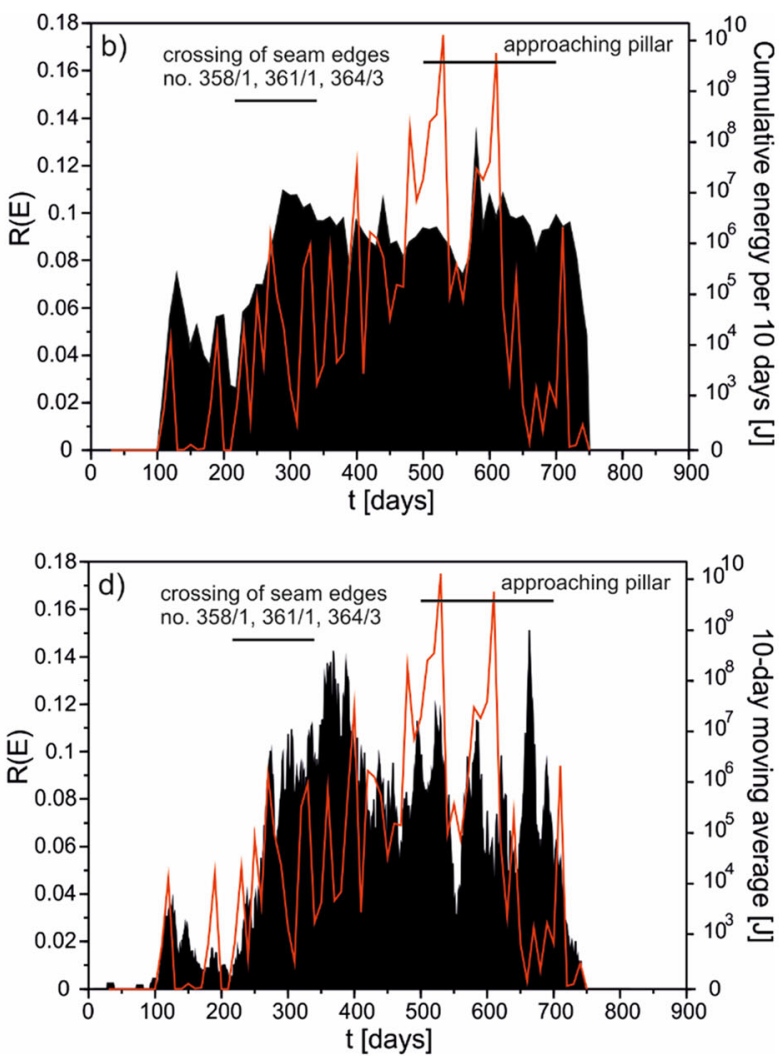

occurrence of an event with energy of $>5 \cdot 10^{5} \mathrm{~J}$ per 10-day interval (red line) and the event frequency per 10-day interval $(\lambda)$ (blue line); and (d) the probability of the occurrence of an event with energy of $\geq 5 \cdot 10^{5} \mathrm{~J}$ per 10-day interval (red line) and the 10-day moving average of energy released

describes the behaviour of materials in terminal stages of failure under conditions of approximately constant stress and temperature. Brehm and Braile (1999) showed that the same statistical model can be obtained from the assumptions described by Das and Scholz (1981). But in this case, the model was derived from fracture mechanics and crack propagation based on an equation which considers relation between the rate of crack half-length, stress drop, stress intensity factor, crack velocity and stress corrosion index. Next, this concept was applied to natural seismicity (e.g. Brehm and Braile 1999; Jiang and Wu 2005; Jiang and Wu 2006). An idea that seismic energy release can be applied to the induced (or anthropogenic) seismicity was introduced by Mendecki (1996), and it is still developed. Mendecki et al. (2019) suggested that mined coal seam can be treated as closed system, analogically to the Voight's sample under pressure, and the occurring rate 


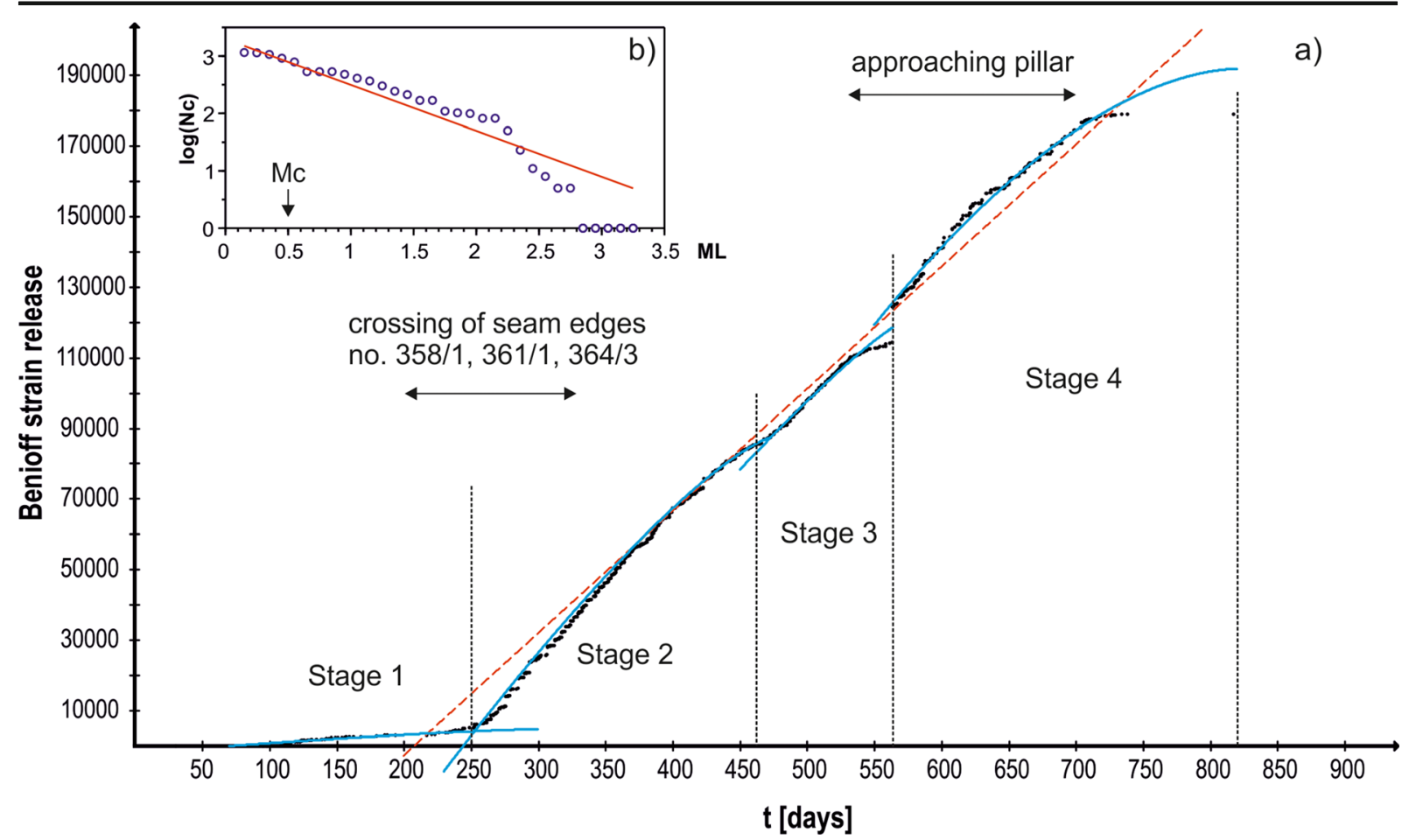

Fig. 9 Results of the Benioff strain analysis: (a) the Benioff plot, black dots are BSR; the red dashed line is a linear trend during the entire period of seismic hazard assessment results; the blue solid

and size of seismic event release is governed by the same physical process. Appearing cracks in the rock mass, reflected as minor seismic events, can result in strong seismic event which correspond to the Voight's sample failure.

The simplified model proposed for the rate at which the Benioff strain is released during a mining tremor sequence prior to a strong event can be presented as follow (Mendecki et al. 2019):

$$
\Sigma \Omega=k_{0}-k\left(t_{f}-t\right)^{m}
$$

where $\Omega$ is the Benioff strain; the sum denotes the cumulative procedure; $k_{0}, k$ and $m$ are constants; and $t_{f}$ is the time of failure in the case of $m<1$, or the end of the sequence in the case of $m>1$. By definition, if the value of $m$ is lower than 1.0, the release curve is regarded as accelerating-like; if $m$ is higher than 1.0, then the release curve is regarded as quiescence-like (Jiang and Wu 2005; Jiang and $\mathrm{Wu}$ 2006). The process of BSR for mining tremors has to fulfil two criteria for the sequence: (Brehm and Braile 1999) the magnitude of completeness $\left(M_{c}\right)$ must be known, and the dataset should have a frequencymagnitude distribution (FMD) for an appropriate time lines correspond to the four BSR models; (b) the frequencymagnitude distribution calculated for the entire catalogue; blue circles, observed frequencies, and red line, FDM model

interval preceding the main-shock; and (Convertito et al. 2012) there are no interfering events. An interfering event is considered to be any event greater than $M_{L} 0.5$ less than the mainshock, located near the mainshock in both time and space. In this case, it corresponds to c.a. 2.5-order difference in a power of tremor energy. The strongest event was of $10^{8} \mathrm{~J}$; thus, each tremor of c.a. $5 \cdot 10^{5} \mathrm{~J}$ and stronger was assumed as the interfering event. This discrimination criterion was elaborated according to Brehm and Braile (1999) who suggested 0.5 magnitude unit less than the mainshock as the limit. Moreover, caution must be exercised when evaluating precursory sequences containing events within $5 \cdot 10^{3} \mathrm{~J}$ (ca. 1 magnitude unit) of the mainshock because a single precursory event may account for the entire increase in energy release for an acceleration sequence. Therefore, the objective of the evaluation is to analyse the behaviour of the acceleration sequences and determine its characteristics (see Brehm and Braile 1999). The mainshocks (large mining events) were chosen based on the assumption that the strong event usually has a greater local magnitude than the background which can be represented by an event swarm ranging from $M_{c}$ to $M_{L} 2.0-2.5$. In the Upper 
Silesia Coal Basin, this corresponds to energies ranging from $E_{\text {min }}$ to $10^{5}-10^{6} \mathrm{~J}$ (interfering event criterion). The $M_{c}$ or $E_{\text {min }}$ represents the threshold of the seismic catalogue completeness (Mendecki et al. 2019). In this study, the $M_{c}$ was set as 0.5 which corresponded to the minimum energy of approximately $8 \cdot 10^{2} \mathrm{~J}$. Those values were set based on the assumption that the magnitude of completeness corresponded to the highest magnitude frequency (Fig. 9b). The entire catalogue was filtered and events smaller than $M_{c}$ were removed. Interfering events were assumed as those exceeding the energy of $10^{6} \mathrm{~J}$. Because of the occurrence of an atypical series of high-energy events, the second criterion was difficult to fulfil for the event energy of $10^{5} \mathrm{~J}$. Additionally, visual inspection of the Benioff plot identified those sequences which did not finish with a large-energy event, but the curve clearly indicated the end of the release process and that the next sequence had started.

The analysis of the cumulative Benioff strain plot indicated four stages of release. Table 1 contains the results of non-linear regression (non-linear least-square method) for the BSR models at each stage. The BSR started with the first day of the longwall mining. The first stage, which can be defined as the initial stage, is represented by the quiescence-like model during the period of 0-250 days. At the beginning, the seismic energy release, and therefore the BSR, was small and acceleration did not occur. Similarly, other models were also identified as the quiescence-like type of released BSR sequences (Table 1, Fig. 9a). The next three stages lasted for the following periods: $250-473$ days, 473564 days and from the 564th day up to the day of the last event occurrence. All four interpreted sequences were characterized by asymptotic curves indicating maximum Benioff strain release.

The acceleration-like behaviour of the BSR can be noticed between days 250 and 300 which corresponds to the transition between the interpreted stages 1 and 2 . This acceleration is visible as the sudden change in BSR slope, but the convex shapes of the 1 stage and the 2 stage BSRs make it impossible to fit the appropriate accelerating BSR curve. Therefore, the transition from stage 1 to stage 2 presents a "pseudo-acceleration-like" character due to the release of accumulated stress. Moreover, this transition occurred when the longwall face was approaching and crossing the zone affected by overlayed seam edges nos. 358/1, 361/1 and 364/3, and it resulted in sequences of high-energy tremors. However, the further run of the BSR convinced us that this transition period is a superimposition of two quiescence-like processes with different rates (corresponding to the stage 1 and stage 2), and any acceleration model was taken into account in the parameter estimation. Such a situation was interpreted as changes in the rock mechanics of the roof rocks resulting from an increase of fractures in the rock mass caused by caving as well as the increase of seismicity damaging rocks.

The interpreted 4 stages showed 4 quiescence-like models with varied slopes. To facilitate the interpretation, we fitted the straight line (Fig. 9a, red dashed line) which represents the general trend (slope) of seismic energy release after the initial stage (the stage 1). If the BSR runs below the straight line, we called it "a deflation period", and if over the line, "an inflation period". The period of transition from the initial stage to the higher rate of the BSR (the second) was characterized by seismic energy release deflation. Deflation of the BSR was interpreted as a decrease in the ability of rock mass to release seismic energy, and this resulted in the signification accumulation of strain energy in rocks. Finally, this led to the occurrence of high-energy tremors which were released when critical stress level in rocks (discontinuities in rocks) was exceeded. Deflation was observed between the first and second stage, as well as during the third stage. Moreover, the deflation was associated with a decrease of the $b$-value (Fig. 7) as well as the increase of seismic hazards (Fig. 8b), which resulted from the occurrence of a significant number of

Table 1 The BSR model parameter calculations for four identified stages

\begin{tabular}{|c|c|c|c|c|c|}
\hline Stage no. & Period & $k_{0}$ - parameter & $k$-parameter & $m$ - parameter & $R^{2}$ \\
\hline 1 & $0-250$ & 4737.61 & 3.57 & 1.32 & 0.89 \\
\hline 2 & $250-473$ & $87,727.4$ & 80.8 & 1.28 & 0.99 \\
\hline 3 & $473-564$ & 118,440 & 181.7 & 1.14 & 0.97 \\
\hline 4 & $564-820$ & 191,166 & 3.77 & 1.76 & 0.99 \\
\hline
\end{tabular}


high-energy events. In both cases, the deflation appeared when the longwall face was approaching zones located below the old edges of far-distant coal seams.

The inflation of the BSR was interpreted as the increase of the ability of rock mass to release seismic energy. This can represent a situation when accumulated strain energy was easily released, and the $b$-value was relatively high, i.e. in the last stage. This stage corresponds to the period when low-energy seismicity increased. The terminal stage was dominated by low- and medium-energy events, but high-energy events also occurred and were numerous. This suggests that those events were associated with the distortion of the strain-stress equilibrium due to the presence of the protecting pillar.

A previous study (Mendecki et al. 2019) concerned the induced seismicity which occurred in the case of mining seismicity in a studied longwall panel in the "Bobrek" colliery and also the case of mining seismicity produced near the protecting pillar in a longwall panel in one the mines belonging to the Polish Mining Group. The results suggested that heterogeneous geological and mining conditions in hard coal mines are reflected in the pseudoacceleration-like type of the BSR, and the location of the events is in accordance with the longwall face advance; additionally, the events were located mainly in the seam and its surroundings. Discussed patterns of seismicity and the dominated quiescencelike processes of the BSR indicated that the seismicity associated with the longwall panel was not directly caused by the mining and roof rock caving. The observation presented suggests that the mining edges located at far distances from the studied panel may have an influence on the seismicity.

\section{Conclusions}

The specific system of coal seams edges leads to highly uneven stress distribution in the rock mass. Underground workings can breach the stress-strain equilibrium which exists in the area of these edges and initiate geomechanical processes. Tremors correlated with these processes are strong and sometimes comparable with those with a tectonic origin. As has been shown in thus article, the stress release near the cluster of coal seams edges might be activated despite the lengthy vertical distance between the extracted coal seam and these remainders. For this purpose, the frequency and energy distributions of tremors were analysed.

The highest number of strong tremors occurred approximately $70 \mathrm{~m}$ from the longwall face and from the side of unmined coal seam no. 408. These tremors occurred inside and outside of the longwall panel. However, most of the seismic energy was released by tremors whose foci were located approximately $220 \mathrm{~m}$ from the longwall face and from the side of unmined coal seam no. 408. The longwall mining of coal seam no. 408 disturbed the stress-strain equilibrium state occurring close to the edges of far-distant coal seams nos. 364/3, $364 / 1,361 / 1$ and 358/1, and this process was responsible for the triggering of strong tremors. The process of fracturing took place most likely in the thick layer of sandstones deposited below coal seam no. 401 (i.e. $250 \mathrm{~m}$ above coal seam no. 408) and at a close vertical distance from the edges of the seams belonging to the 300 series. Some of the strong tremors were correlated with the edges of layers of the closer coal seam, no. 405/ 2. Generally, it can be concluded that the strong tremors that occurred during the longwall mining of coal seam no. 408 were rather triggered than induced.

According to the Benioff plot, four stages characterized by different seismicity and rate of seismic energy release can be distinguished. Based on the observed Benioff plot of the average rate of seismic energy release, deflation and inflation areas have been distinguished. The deflation of Benioff plot suggests that the strain energy was stored in the rock mass. This energy was released in steps by the strong tremors. These periods are correlated with low values of parameter $b$ of the G-R distribution and an increase in seismic hazard. A comparison of these observations with the longwall face advance suggests a relationship with the approach of the longwall face to the zones covered by the cluster of far-distant coal seams edges. Inflation of the Benioff plot also took place. During these periods, the vast number of weak tremors occurred, and parameter $b$ of the G-R distribution increased. The accumulated strain energy was released also by the vast number of low- and medium-energy tremors. This was especially observed during the final stage and was correlated with the destruction of the established pillar.

It seems that most interesting part of BSR curve is the transition between the stage 1 and stage 2 . In our interpretation, we assumed that it is a superposition of two quiescence-like processes. Therefore, it can be interpreted that the lack of a clear acceleration-like 
process in the dataset indicates that the nucleation process of the high-energy events did not start in the area of the longwall panel but beside it. May be the strongest event in the catalogue is rather triggered than induced (Mendecki et al. 2020). Oppositely, the transition, which has the accelerating-like behaviour, could show that it was caused by the mining through stress release, which in turn induced seismicity correlated to the previous longwall panels. The appeared interpretation issues indicated that the study on the BSR in mines is worth for further research and elaboration.

Open Access This article is licensed under a Creative Commons Attribution 4.0 International License, which permits use, sharing, adaptation, distribution and reproduction in any medium or format, as long as you give appropriate credit to the original author(s) and the source, provide a link to the Creative Commons licence, and indicate if changes were made. The images or other third party material in this article are included in the article's Creative Commons licence, unless indicated otherwise in a credit line to the material. If material is not included in the article's Creative Commons licence and your intended use is not permitted by statutory regulation or exceeds the permitted use, you will need to obtain permission directly from the copyright holder. To view a copy of this licence, visit http://creativecommons.org/licenses/by/4.0/.

\section{References}

Brehm DJ, Braile LW (1999) Intermediate-term earthquake prediction using the modified time-to-failure method in southern California. Bull Seismol Soc Am 89(1):275-293

Convertito V, Maercklin N, Sharma N, Zollo A (2012) From induced seismicity to direct time-dependent seismic hazard. Bull Seismol Soc Am 102(6):2563-2573. https://doi. org/10.1785/0120120036

Das S, Scholz CH (1981) Theory of time-dependent rupture in the earth. J Geophys Res Solid Earth 86(B7):6039-6051. https://doi.org/10.1029/JB086iB07p06039

Drzęźla B, Białek J, Jaworski A, Bańka P, Słapa W (1991) Distributions of the number and energy of mining shocks nearby active longwall excavations (in Polish). Publs Inst Geophys Pol Acad Sc M-15(235):197-202

Dubiński J, Konopko W (2000) Rockbursts: assessment, forecasting and combating (in polish). Central Mining Institute, Katowice

Dubiński J, Wierzchowska Z (1973) Methods for the calculation of tremors seismic energy in the upper Silesia (in polish), scientific works of central mining institute, statement no. Katowice 591:3-23

Dubiński J, Stec K, Bukowska M (2019) Geomechanical and tectonophysical conditions of mining-induced seismicity in the Upper Silesian Coal Basin in Poland: a case study. Arch Min Sci 64(1):163-180. https://doi.org/10.24425 /ams.2019.126278
Gołda I, Kornowski J (2011a) Application of the GutenbergRichter distribution to forecast seismic hazard together with assessment of its uncertainty (in Polish). Min Geol Gliwice $6(3): 49-62$

Gołda I, Kornowski J (2011b) Seismic hazard and seismic rockburst hazard. Part II: quantitative assessment and analysis of its uncertainty (in Polish). Sci Works Central Min Instit: Mining and Enviroment, Katowice 4(2):116-132

Hasegawa HS, Wetmiller RJ, Gendzwill DJ (1989) Induced seismicity in mines in Canada - an overview. Pure Appl Geophys 129(3-4):423-453. https://doi.org/10.1007 /BF00874518

Jiang C, Wu Z (2005) Test of the preshock accelerating moment release (AMR) in the case of the 26 December 2004 mw 9.0 Indonesia earthquake. Bull Seismol Soc Am 95(5):20162025

Jiang C, Wu Z (2006) Benioff strain release before earthquakes in China: accelerating or not? Pure Appl. Geophys. 163:19651976. https://doi.org/10.1007/s00024-006-0107-1

Kijko A, Lasocki S, Graham G (2001) Non-parametric seismic hazard in mines. Pure Appl Geophys 158(9-10):1655-1675. https://doi.org/10.1007/PL00001238

Kusznir NJ, Ashwin DP, Bradley AG (1980) Mining induced seismicity in the north Staffordshire coalfield, England. Int J Rock Mech Min Sci Geomech Abstr 17(1):45-55. https://doi.org/10.1016/0148-9062(80)90005-4

Lasocki S (1994) Parametric or nonparametric analysis of induced seismicity sequences. Proceedings of rock mechanics in petroleum engineering: Eurock '94, Delft, Netherlands, Society of Petroleum Engineers, Balkema: 639-644. https://doi. org/10.2118/28107-MS

Lasocki S (1995) Statistical distribution of seismological events (in Polish). In: Drzęźla B, Dubiński J, Fajklewicz Z, Goszcz A, Marcak H, Pilecki Z, Zuberek WM (eds) Guide for mining geophysicist, 2nd edn. CPPGSMiE PAN, Kraków, pp 174 189

Lasocki S, Orlecka-Sikora B (2008) Seismic hazard assessment under complex source size distribution of mining-induced seismicity. Tectonophysics 456(1-2):28-37. https://doi. org/10.1016/j.tecto.2006.08.013

Leptokaropoulos K, Staszek M, Cielesta S, Urban P, Olszewska D, Lizurek G (2017) Time-dependent seismic hazard in Bobrek coal mine, Poland, assuming different magnitude distribution estimations. Acta Geophysica 65(3):493-505. https://doi.org/10.1007/s11600-016-0002-9

Mendecki AJ (1996) Seismic monitoring in mines. Springer Science \& Business Media

Mendecki MJ, Wojtecki Ł, Zuberek WM (2019) Case studies of seismic energy release ahead of underground coal mining before strong tremors. Pure Appl. Geophys. 1-22. https://doi. org/10.1007/s00024-019-02144-0

Mendecki MJ, Szczygieł J, Lizurek G, Teper L (2020) Miningtriggered seismicity governed by a fold hinge zone: the upper Silesian Coal Basin. Poland Eng Geol, in press 274:105728. https://doi.org/10.1016/j.enggeo.2020.105728

Mutke G, Dubiński J, Lurka A (2015) New criteria to assess seismic and rock burst hazard in coal mines. Arch Min Sci 60(3):743-760. https://doi.org/10.1515/amsc-2015-0049

Stec K (2007) Characteristics of seismic activity of the upper Silesian Coal Basin in Poland. Geophys J Int 168(2):757768. https://doi.org/10.1111/j.1365-246X.2006.03227.x 
Stec K (2012) Focal mechanisms of mine-induced seismic events an explanation of geomechanical processes in the area of longwall 6, seam 510 in hard coal mine Bobrek-centrum. Arch Min Sci 57(4):871-886. https://doi.org/10.2478 /v10267-012-0057-7

Stec K (2015) Geomechanical conditions of causes of high-energy rock mass tremors determined based on the analysis of parameters of focal mechanisms. J Sustain Min 14(1):55-65

Stec K (2017) Causes of the occurrence of high-energy seismic events based on focal mechanism parameters (in Polish). Bull Min Energy Econ Res Instit Pol Acad Sci 101:19-32

Stec K, Lurka A (2015) Characteristics and seismologic methods of analysis of seismic activity in the upper Silesian Coal Basin (in Polish). Pol Min Rev 1(1):83-93

Stec K, Wojtecki $Ł$ (2011) Characteristics of the mine tremor source mechanism associated with the mining in the seam 510, the longwall 502 in the "Bielszowice" coal mine (in polish). Res Rep Centr Min Inst: Min Environ 2011:61-77

Voight B (1989) A relation to describe rate-dependent material failure. Sci. 243(4888):200-203
Wojtecki Ł, Gołda I (2019) Analysis of stress level during longwall mining of a coal seam with the use of seismic effect method. IOP Conf Series: Earth and Environmental Science 261:012057. https://doi.org/10.1088/1755-1315/261 $/ 1 / 012057$

Wojtecki Ł, Knopik M, Zuberek WM (2016) The influence of a local fault zone on high energy tremor occurrence during longwall mining of a coal seam. Acta Geophysica 64(4): 1164-1175. https://doi.org/10.1515/acgeo-2016-0040

Wojtecki Ł, Konicek P, Mendecki MJ, Gołda I, Zuberek WM (2019) Geophysical evaluation of effectiveness of blasting for roof caving during longwall mining of coal seam. Pure Appl Geophys 177:905-917. https://doi.org/10.1007 /s00024-019-02321-1

Publisher's note Springer Nature remains neutral with regard to jurisdictional claims in published maps and institutional affiliations. 